\title{
Estudios lingüísticos y culturales sobre China. Homenaje a Pedro San Ginés Aguilar
}

\author{
Patricia Amate Núñez
}

\begin{abstract}
AA.VV. 2019. Estudios lingüísticos y culturales sobre China. Homenaje a Pedro San Ginés Aguilar. Granada: Comares, 264 pp.
\end{abstract}

Pedro San Ginés Aguilar (París, 1949) ha sido una figura clave en el desarrollo de los estudios de sinología y de Asia Oriental en la historia de la universidad española. Fue pionero en la enseñanza de la lengua china en el curso 1978-1979 con la primera asignatura de chino en la antigua Escuela Universitaria de Traductores e Intérpretes de Granada. De ahí en adelante los estudios de sinología en España se han ido asentando, contando en la actualidad con grandes investigadores e investigadoras, entre los que desde luego abundan sus discípulos. Son precisamente ellos quienes han hecho posible este volumen, publicado por Comares dentro de la colección Renacimiento de Asia Oriental IX.

La primera reflexión que surge al ojear el manualy en el marco en el que nace el libro, apelando a la máxima de que todo buen sinólogo es un puente entre China y Occidente, hacen de él un volumen de cabecera para todo interesado en estudios sinológicos. 
El volumen está dividido en dos partes: Una primera parte, y la que se trata en esta reseña, centrada en estudios lingüísticos y una segunda parte que se centra en estudios culturales. En la primera parte encontramos los siguientes estudios:

Isabel María Balsas Ureña. Universidad de Granada. 40 años de enseñanza de chino como lengua extranjera en España, Apoyado en un riguroso análisis de fuentes que recogen desde la Conserjería de Educación en China hasta la Junta de Andalucía en España, pasando por un sinfín de documentación centrada en planes de estudio de enseñanza de la lengua china. Balsa es capaz de presentarnos los diferentes periodos por los que ha transcurrido el estudio y enseñanza del chino en Europa, desde los misioneros españoles Martín Rada (1533-1578) y Juan Cobo (1627-1678) como pioneros, hasta la década de los 70 con el homenajeado San Ginés. Su análisis hace una descripción de los 4 tipos de enseñanzas regladas de lengua china que hay actualmente en España, señalando cómo y por qué surgen las enseñanzas y las dificultades que se encuentran a la hora de ser implantadas. Hace además la autora un destacado análisis de las diferentes metodologías utilizadas para la enseñanza del idioma chino. En las conclusiones del capítulo se introduce una reflexión fruto de su investigación en la que destaca la falta de más profesorado preparado para la enseñanza en todos los niveles educativos y más materiales desarrollados localmente, solicitud a la que se suman otros autores que comento a posteriori. Uno de los puntos fuertes de la investigación de Balsa para mí es, sin duda, la reflexión que la autora nos presenta acerca de la importancia de una mejora metodológica en la enseñanza de la lengua china en nuestro país.

Juan José Ciruela. El uso de radicales en el aprendizaje de la escritura china. Este capítulo está dividido en 5 apartados dedicado a la enseñanza de la escritura china y la mejor metodología aplicable para ella, Ciruela, nos habla en la 
introducción del proceso de adquisición de la capacidad lectora en niños haciendo hincapié en el estadio logofográfico, alfabético y ortográfico que sitúa en el orden de aprendizaje. Las diferencias claves entre la escritura alfabética y la escritura china, las partes en las que se encuentra dividido un carácter, el procesamiento de los caracteres chinos, tema candente entre los estudiosos actuales, y que el autor nos explica con detalle desde tres aproximaciones existentes; la holística, la analítica y la híbrida. Resulta interesante la presentación que se nos hace en el capítulo de la técnica de análisis Character Decision Task CDT sus fuertes y desventajas. Entre las desventajas la necesidad de aplicar una novedosa técnica de estudio Ceguera por repetición (Radical-RB) que refuerce los resultados de la CDT. El último apartado del libro es: Implicaciones didácticas en el que el autor nos presenta conclusiones de diferentes estudios realizados sobre el aprendizaje de la escritura china y que él también apoya. En citas de su capítulo: "El conocimiento de los radicales por parte de los estudiantes [extranjeros] afecta al aprendizaje de caracteres (Shen\& Ke, 2007, p.100)". "El nexo entre los estudios existentes centrados en niños chinos y el de aquellos que buscan mejorar el conocimiento y la didáctica de la escritura china entre estudiantes extranjeros, constituye una interesante línea de investigación por la que algunos especialistas han comenzado a interesase".

De acuerdo con las palabras de Ciruela, coincido en que el tema que presenta es de especial relevancia entre los estudios sinológicos contemporáneos y sobre que es necesario seguir trabajando en esta línea para mejorar la metodología en el aprendizaje de esta compleja escritura.

Nobuo Ignacio López-Sako, escribe el capítulo Ba o Youmu o la Importancia de < leer la situación >> en la comunicación en lengua japonesa: un reto para el aprendiz japonés. Como nos indica el título este apartado no se centra en la lengua y cultura china sino que está centrado en cuestiones lingüísticas y 
culturales, podríamos decir un estudio sociolingüístico del país nipón. López comienza su tema de investigación a través una llamativa noticia de prensa en la que la importancia de la lectura de la situación cultural en el país del sol naciente es cuestión incluso de vida y muerte como ya explica la noticia periodística. A partir de ahí, el autor nos permite conocer diferentes matices en el estudio de la lengua japonesa y el uso correcto de las partículas que la compone dentro de las relaciones endogrupales en la jerárquica sociedad nipona, especialmente de; senpai, doryo y kohai. Además, López nos hace continuas comparaciones entre la lengua hispana y la nipona para que los lectores no investigadores o jóvenes investigadores en este campo podamos observar y citando el texto "como para una oración tan simple como < < Hoy es sábado>> existen en japonés al menos tres formas diferentes de representarlo lingüísticamente, dependiendo del nivel de formalidad del verbo (...) en definitiva, la proposición <<Hoy es sábado.>> en español no tiene connotación social, se puede utilizar en cualquier contexto, mientras que, a la hora de enunciar cualquiera de las tres versiones en japonés, el hablante automáticamente se posiciona socialmente respecto al receptor del mensaje ". Como conclusión y de nuevo en palabras del autor "la tarea de comunicarse en lengua japonesa puede resultar realmente complicada". Este capítulo y a modo de reflexión personal hace entrever en comparación con el resto de los temas lingüísticos centrados en estudios chinos que encontramos en el libro, la diferencia abismal que existe entre la cultura-lengua japonesa y la cultura-lengua china.

Lucía Luque Nadal y Juan de Dios Luque Durán. Los co-compuestos o compuestos coordinativos en chino: una perspectiva translingüística. Los autores nos hablan de los co-compuestos, un fenómeno que se da en diferentes idiomas de Asia, Europa oriental, Nuevas Guinea, entre otros. A partir de ahí ambos 
autores nos hacen una definición de su tema de estudio y la metodología que usan "la lexicogenesis tiene una orientación generalista e investiga, de manera global y comparada, todos los patrones y fórmulas de las que sirven las diferentes lenguas del mundo para crear nuevas palabras y conceptos. (...),'tipología léxicosemántico complementa lo anterior en tanto cuanto que, a la explicación cognitiva, le añade una explicación económica-posibilista de las creaciones léxicas" en el último apartado del capítulo nos hacen una división de los cocomponentes que existen, aditivos, sinonímicos, genéricos y colectivos, escalares, aproximativos y figurativos profundizando en las características que presentan cada uno. Sin duda este capítulo ayuda a ampliar la visión de los diferentes puntos en común de los diferentes idiomas que existen en el mundo, podríamos decir, que es un tema que nos acerca más que nos diferencia pudiendo establecer estándares comunes para el estudio de las lenguas en el mundo.

Consuelo Marco Martínez. La formación de las palabras en chino mandarín. Marco hace una presentación de la lengua china desde una de las partes más llamativa de ella; el carácter. Para ello nos explica la estructura morfológica de éste y realiza un estudio que nos explica en este capítulo los fonemas de formación de palabras: La reduplicación, afijación, composición y parasíntesis. A su vez nos distingue entre "carácter", "morfema", "sílaba" y "palabra". A través de esta distinción Marco nos muestra su objetivo en este estudio: Destruir tres mitos "la concepción del chino como lengua aislante, monosilábica y carente de gramática". Con este minucioso análisis que nos presenta la autora nos hace llegar a la siguiente conclusión: "queda comprobado que actualmente el chino mandarín no es una lengua aislante ni monosilábica, frente a lo que sucedía con el chino clásico". Este capítulo trata de uno de los que más refuerza la actual tesis sobre la composición de la lengua china entre sinólogos. 


\section{P. Amate Núñez \\ Reseña a VV.AA: 2019. "Estudios lingüísticos y culturales sobre China" \\ Sabir. International Bulletin of Applied Linguistics, 1: 180-189}

Gonzalo Miranda Márquez. Características representativas de la escritura china y estrategias para su aprendizaje y enseñanza. Miranda comienza su investigación hablándonos de la practicidad del chino en el mundo contemporáneo a la vez que nos explica lo sorprendente de China, en las propias palabras del autor: "Mientras que prácticamente el resto del mundo comparte los mismos modelos de pensamiento, ellos han mantenido sus ideales propios, que continúan siendo una incógnita para los demás". El Miranda, nos hace una reflexión sobre la problemática de las traducciones clásicas sobre la filosofía y cultura china y plantea en su estudio dar respuesta a dos cuestiones fundamentales: ¿Qué aspectos de la lengua china dificultan tanto el aprendizaje? Y ¿nivel de dificultad que conlleva el aprendizaje de la escritura china (...) y por ende la cantidad de esfuerzo requerido para estudiarla, es el mismo para todos los extranjeros? Para buscar respuesta el investigador presenta diferentes apartados en su estudio: Características representativas de la escritura china en el que su análisis hace una reflexión sobre que, la misma escritura en China es utilizada por diferentes gentes-grupos, podríamos decir étnicos o simplemente pobladores de diferentes regiones en China, pueden tener diferentes pronunciaciones para un mismo carácter. Hace además Miranda, reflexiones sobre la homofonía de la lengua y las dificultades por las que pasamos, creo, la mayoría de los extranjeros a la hora del estudio de la lengua china. Este autor hace a mi parecer, otra reflexión interesante y es la importancia que tiene el docente en el aprendizaje por parte del alumno del idioma, en la que coincidiendo con Miranda "El docente debe presentar la información del modo más ameno posible". Este capítulo cuenta con apartados como: El aprendizaje de la escritura china, la recepción de la información, la comprensión de la información y la memorización. En cuestiones finales el autor nos presenta al igual que Ciruela la importancia del reconocimiento de los radicales chinos en el aprendizaje de la escritura. Por último Miranda, nos deja 
pregunta; la posibilidad de que la escritura china sufra una nueva reforma, y de nuevo en sus palabras: "Es posible afirmar que la escritura china ayuda a los hablantes a discernir con claridad los conceptos de su propia lengua". En conclusión, este autor nos habla de que sin un buen método el aprendizaje de la escritura china se hace arduo y más complejo de lo que podría ser si se cuenta con una buena metodología de enseñanza.

Antonio Pamies Bertrán. La fraseología a través de su terminología. Pamies nos presenta un glosario que establece un balance para ayudar a los lexicógrafos a orientarse a pesar de las polémicas doctrinales que motivaron a los términos que el autor nos presenta. En la introducción nos enseña la metodología que utiliza para su investigación. Sin duda, muestra un prolijo muestrario aparentemente empírico, al reunir un capítulo un glosario fraseológico que incluye definiciones, usos y reflexiones sobre: Antiproverbio, cita no-sentenciosa, colocación, comparación estereotipada, compuesto, construcción de verbo soporte construcción onímica, contrarrefrán, culturema, dialogismo, enunciado de valor específico, enunciado fraseológico, eslogan, estereotipo, fijación, fórmulam frasema, fraseografía, fraseología, fraseologismo, fraseotérmino, frase proverbial, idiomaticidad, lema, locución y tipos, máxima, multilexematicidad, paremia, phrasal verb, polilexicalidad, pragmatema, proverbio, refrán, unidad fraseológica, verbo sintagmático y wellerismo. Convierte este capítulo en un glosario que sirve de cabecera a investigadores noveles y no noveles dedicados a la lingüística en general y en especial a la lingüística china.

Ramón N. Prats. Traducción sin traición: Reflexiones sobre la traducción del tibetano clásico. Prats en su investigación comienza realizando una amplia contextualización del uso del tibetano, desde la zona geográfica en la que se 
habla, la familia lingüística a la que pertenece hasta el gran patrimonio de la civilización tibetana, todo ello para llevarnos a su objeto de estudio; la problematización a la hora de las traducciones a otras lenguas de los textos tibetanos. En el capítulo de este autor encontramos diferentes apartados. En el apartado Lengua aislante y aglutinante llama la atención la comparación que hace del tibetano con las lenguas china y vietnamita. Prats, nos realiza una síntesis sobre la escritura tibetana y como ésta repercute a la hora de las traducciones. Sin embargo, desde mi punto de vista uno de los atractivos más importantes del texto de Prats se encuentra presente en su apartado Reflexiones sobre la teoría de la traducción en las que este investigador nos habla de las líneas generales para que se produzca una buena traducción en lenguas lingüísticamente y culturalmente muy alejadas, y que coincido totalmente. Estas son:

- Conocimiento profundo de la lengua de origen.

- Un óptimo conocimiento de la disciplina que se trata en el texto.

- Un excelente conocimiento de la lengua de destino.

Traducir implica en palabras del autor: "En primer lugar entender y luego trasladar".

Prats, en su estudio nos ayuda a entender las diferentes etapas por las que ha pasado la traducción de textos tibetanos y como apartado estelar de la investigación nos presenta un ejemplo de testo traducido en el que deja expuesto todo lo anteriormente expuesto acabando con todas las duda que hayan podido surgir entre los lectores.

Zhang Zheng Quan. Reflexiones sobre la motivación morfológica de las palabras compuestas del chino moderno. El capítulo de este investigador está centrado como el título nos indica, en la motivación morfológica de las palabras 
compuestas del chino moderno. Como ya hemos visto en capítulos anteriores a través de las investigaciones de otros autores, la atención en la motivación morfológica de las palabras chinas, según afirma el autor, se centra en que todas pueden ser analizadas en lexemas plenamente significantes. Zhang nos habla de componentes flexibles y activos; la bisilabización sinónima, el cambio de orden entre los mismos componentes para conseguir un cambio de significado y el cambio de orden entre componentes sinónimos para un cambio semántico. Todo ello acompañado de ejemplos fácilmente entendibles para cualquier estudioso de la lengua china. Otro punto clave del análisis de este investigador en su capítulo es la sencilla explicación que hace de la estructura sintáctica de las oraciones en lengua china, dividiéndola en sujeto-predicado (y todos los predicados que existen en esta lengua). Previo a la conclusión el autor nos hace reflexionar sobre otro asunto importante para aquellos que dedicamos nuestra vida al chino y que nos ayuda bastante en su aprendizaje, "las palabras compuestas chinas son altamente explicativas, debido a sus componentes plenamente significantes, flexibles y activos, y su estructura sintagmáticosintáctica completamente analizable". Por último, en la conclusión Zhang nos repite algo que hemos ido observando a los largo de capítulos previos y que se presenta como síntesis de su estudio "la motivación morfológica de las palabras compuestas del chino moderno, podemos hacernos ya una idea de la de su léxico general, ya que las mismas son su absoluta mayoría y constituyen aproximadamente un $89 \%$ del lenguaje formal".

En mi opinión y a modo de conclusión, Estudios lingüísticos y culturales sobre China. Homenaje a Pedro San Ginés, no solo nos habla de China, sino que nos sumerge en estudios lingüísticos que engloban a la gran mayoría de países del continente asiático. Este libro, en el que cada capítulo se convierte en un interesante artículo sobre lingüística y cultura, cuenta con ricas fuentes 


\section{P. Amate NÚñez}

Reseña a VV.AA: 2019. "Estudios lingüísticos y culturales sobre China"

Sabir. International Bulletin of Applied Linguistics, 1: 180-189

bibliográficas que ayudan al investigador- lector a profundizar más en el tema que desee.

Es pues sin duda este Homenaje un compendio de investigaciones que se complementan entre sí y que hacen de ello un ejemplar de cabecera para cualquier especialista, o no, en estudios lingüísticos y culturales sobre China, que desee ampliar sus conocimientos sobre el panorama de los estudios más destacados llevados a cabo por diferentes universidades españolas en sinología. 